\title{
Designer's Ethical Responsibility and Ethical Design
}

\author{
Ahmet Atak*, Aydın Şık \\ Department of Industrial Product Design, Institute of Natural and Applied Sciences, Gazi University, Turkey
}

Received May 24, 2019; Revised July 1, 2019; Accepted July 12, 2019

Copyright $@ 2019$ by authors, all rights reserved. Authors agree that this article remains permanently open access under the terms of the Creative Commons Attribution License 4.0 International License

\begin{abstract}
Design affects the entire lifespan of a product. Humans design ideas in their environments, especially to meet their own needs. People come to design ideas and abilities from various objects and events in nature, and use these to increase their design capabilities. With the increase in human population, proliferation of product needs, and the dangerous use of products, the ethical risks have increased. The risks within unethical designs have now reached all levels of human life. Products have been introduced to the market without considering their ethics, and in many of them, only the material purpose has been pursued, instead of the benefit to humanity. This research focused on the goal of the product designers, which is to design and develop a product, while contributing to the awareness that the product needs to be subjected to both risk and ethical analyses as with all other requirements. The dominant task of this study is to enable designers and their designs to develop their own ethical discourse and concepts. In doing so, the most forward aim is to not damage humans, but to design what is useful. The impact on the designer is to have ethical responsibility for their designs.
\end{abstract}

Keywords Design Ethics, Engineering Ethics, Technical Ethics

\section{Introduction}

Design and ethics have both entered the life of human beings to meet their needs, and have evolved through their interactions with the environment. People in prehistoric times met their needs by making various tools for shelter and hunting. Their passion for aesthetics and art is evident in the way that they expressed themselves. This passion for art and beauty laid the groundwork for the creation of beautiful and aesthetic designs. "In some cases buried in the grave, the carbonized marks of the coffin in which they were placed and the iron nails used in the closure of the coffin could also be detected within the grave structure" [1]. In fact, various coffin designs for burial in the ground or traces of boat designs to be buried under water have been found. Many such product designs-including coffins, boats, ornaments, kitchen utensils, and hunting appliances - which have emerged from ancient times during archaeological excavations, are exhibited in numerous museums globally, such as in the British Museum in London.

The good designs have progressed alongside the development of information and technology. However, as human beings have gained more, they have the ambition of dominating nature. This ambition has made them more masterful in the field of good design. However, it has been forgotten that the world is a finite resource. Perhaps they did not want to think and took a selfish approach. This has become a universal problem. For example, with increasing environmental pollution, decreasing resources, autonomous vehicles, artificial intelligence, robotics, autonomous factories and transportation, and autonomous houses and appliances, people are becoming unhealthy and obese. Humans remain an ethical problem [2]. Metzler points out the necessity of taking ethical responsibility:

It is also important to protect him as much as taking advantage of the living environment and to avoid behaviors that will disturb his natural balance. Leaving an environment to live in all living beings for future generations is one of the most important tasks that fall to human beings [3].

Torunoğlu (2014), in a lecture entitled, "Environmental ethics and environmental engineering" both reports on and questions the design-ethics relationship. He asks people to think about the dilemma today, and ask the following oppositional questions:

- An automobile factory? The potato field? (Autonomous vehicles produce people who do not walk, are unhealthy, and obese. Workers in the potato fields, however, do not stop. They are always on the move, so they live healthily.)

- $\quad$ Energy? Rivers? (Energy from fossil fuels makes our lives easier, but it is causing air pollution. Renewable energy from rivers is more environmentally friendly.)

- Dishwasher? Forests? Both? (The dishwasher makes our life easier. Unfortunately, dishwashing detergent is harmful to the environment and forests.)

- Can war be questioned? Is it ethical to design instruments of war? 
- Is it ethical to take a share of the trade that emerged at the end of any war?

- The last question for ethics is: Is it human-centric ethics? Life-centric ethics (to protect any life)? Or both?

Torunoğlu (2014) also emphasizes the ethical responsibility of the designs for people and the environment:

Nature's rights should be the subject of the project and the design process; engineering should cease to be the only branch of science that is limited to the extent that technical solutions allow it to make the most profit. As a value, the dominant rule should be the pollution prevention approach, instead of the polluter pays.

We must question what it is that we want. Design is shaped in an idea, which then transforms into geometry and then product. In the initial phase, if the designer considers ethical behavior as a necessity, we can ultimately leave our children a better world, without causing them harm.

In terms of ethical design, the most difficult sector to consider involves design that eliminates life. Weapon design is one of the oldest, stable, and long-lasting mechanisms that can be used in wars [4]. What is unethical in the defense sector is that scientists and engineers have designed, invented, and experimented with tools that eventually lead to loss of human life. The most classic example is "the atomic bomb." In 1945, the atomic bomb was studied for a long time, both scientifically and in terms of technical ethics, and whether scientists could be held responsible for the atomic bombs that were used on Hiroshima and Nagasaki. The basis of these scientific debates was the principle that no one can be held responsible for what someone else is doing.

The scientists working on the Manhattan-Project had one goal: developing an atomic super weapon that would help the U.S. secure victory over the Axis powers during World War II. This project came as the result of Albert Einstein learning that Germany was developing atomic weapons [5].

Using the atomic bomb was decided by politicians before being finally prepared by the soldiers. From the development of the atomic bomb to its explosion, there were many steps that scientists and engineers could not attend to or decide [6]. Many tasks related to a product, such as scientific studies, definition of requirements, design, production, testing, implementation, service, and lifecycle follow-up are performed not by one person, but by different occupational groups. In some cases, it is not easy to separate these tasks from each other. A lot of homework is done by not only a single person, but by a joint participation of professionals from different fields. Additionally, in some cases, while research and development is on one side, and producing and using something on the other, it is not easy to separate them from each other. Therefore, Krohn and Weyer (1989) specified:
"The risks of the research are the risks of society." Another way of saying this is: "The unethical of the design and engineering are the unethical of society."

Previously, ethical rules were based solely on religious and national motives, while industrial humanitarian values and rules needed to be considered as a whole with the advances of industrialization and communication. For this purpose, various national and international ethical institutions and organizations have emerged. The first instance of professional rules being used was in the field of medicine in 1793, but the ethics rules for engineering were issued by the American Chamber of Electrical Engineers in 1912 [7].

Ethical issues in engineering activities were initially introduced by the engineers themselves. For example, Friedrich Dessauer (1926) stated that the meaning of technology is service to humanity and that engineers are responsible for this [8]. In addition, the codes of engineering ethics were published by the World Engineers Association on October 5, 1977 [9].

Ethical codes and ethical principles have grown in every field of science, from scientific institutions and organizations to universities and academia, from which evolved the ethics of the technique [10]. Turkey is one of the developing countries to have begun work in this area. The TMMOB (Union of Chambers of Turkish Engineers and Architects) Code of Professional Conduct, adopted in April 2003, is a good example of such attempts in Turkey [11]. The ethical principles and rules in many engineering organizations and institutions in Turkey have been taken into account by the initiative. In the public sector, Law number 5176 on the establishment of an ethics committee for public servants and amending some laws has been adopted on May 25, 2004 [12]. The regulation on the principles of ethical conduct of public servants was enforced on April 13, 2005 [13]. Then the ethics committee attached to the Turkish Government issued an "Ethical Guide" in April 2012 for public officials [14]. The United Nations also has its international rules of conduct for public officials (United Nations International Code of Conduct for Public Officials 1996). Not only in the public sector, but also in many private companies, some of these ethical rules are published online [15].

In this era of relentless change, technological developments have become harsher and have rapidly refined some concepts such as ethics with environmental and humanitarian responsibilities. This can be exemplified by the effects of carbon dioxide emissions from fuel or coal consumption by cars, factories, and households on global warming. Furthermore, another example is the extremely speeded research and development of biotechnological and microbiological developments in research areas where agricultural machines, tools and equipment are designed. Here again, there is an unethical misuse of the tools that have been designed; that is, they are being used in a way that is harmful to human beings. The genetically modified 
seeds, or chemicals applied to crops such as insecticides or pesticides, serve to increase fertility while destroying the human or animal organisms that consume them. Some insecticides were used as weapons of mass destruction in the 20th century. Moreover, being on the edge of the digital transformation via artificial intelligence, machine learning, and big data, we should question ourselves now more than ever to set a solid background for ethical principles, because any artificially intelligent and persistently learning organisms, driven by programmed codes without the ability to make decisions based on ethical principles, can harm the world even more than humankind can.

As is evident, the ethical research field in technology is too large. This study aimed to consider only topics linked to the designer's ethical responsibility and design ethics. The paper first defines ethics and design and then the relationship between them. What are universally accepted ethical rules for designers against society and environment have been determined.

The problems faced by the designer in fulfilling the ethical design responsibility and the solutions for them are presented in this study. For designers who have made a design decision, their responsibilities toward basic human values and the ethical issues they may face are examined. While designing products, they participate in many stages and areas of science, technology, and society. It may have been determined that the designer may be forced into hierarchical stages where is no decision allowed. However, there is the fact that the designer has a responsibility to inform their supervisors.

\section{Ethics and Design}

The term ethics is derived from the Greek word "ethos." Ethics, in its simplest definition, refers to the science of morality. "Being, knowledge, and value" are three main branches of philosophy; ethics tries to understand the nature of the notion of morality in order to distinguish ethics, correct behavior, and misconduct, which are branches of values philosophy. Other ethical classifications are meta-ethics, normative ethics, and applied ethics, which are seen in analytical philosophy.

"The ethics guidelines" of the Turkish Government Ethics Committee for Public Officials describe ethics as follows: "Ethics is the whole of the principles of ethics that are fundamental to one's behavior. In other words, ethics are guidelines, principles and standards that help people to determine how things should be done." Ethics is also a process during which, when taking decisions and implementing them, we act by adhering to certain values [16].

Arthur Schoppenhauer stresses the difficulty of explaining what values and where ethical codes are based when he said, "Moral preaching is easy, but it is difficult to cause morality" [17]. Ethical principles seek answers to these requirements. The Cambridge Dictionary defines "principle" as a basic idea or rule that explains or controls how something happens or works. Moreover, "principle" is approving a moral rule or standard of good behavior.

General principles of ethics include universal values such as: justice, equality, honesty and integrity, impartiality, responsibility, human rights, humanism, commitment, the rule of law, love, respect, tolerance, bravery, democracy, positive human relations, increased service standards, transparency, rights and freedoms, and resistance to illegal orders [16]. General unethical behaviors include: discrimination, favoritism, bribery, psychological intimidation, neglect, exploitation, selfishness, corruption, violence, oppression, aggression, recruitment, insults, profanity, physical or sexual harassment, abuse of duty or power, and gossip [16]. Standards of Ethics can be listed as follows: honesty, attention, freedom, dignity, education, social responsibility, equality of opportunity, legality, mutual respect, and efficiency [14]. The code of ethics consists of the terms, "ethics" and "code." Ethics is an ethical science: "moralibus scientiis" [18]. Based on the areas where ethics are used, it can be called technical ethics, health ethics, scientific ethics, etc.

Codes are a collection or catalog of ethical rules applicable to the intended area of use and the associated individuals. Well-known examples are "The Code of Ethics of Electrical Engineering (IEEE)," the German Engineering Association (VDI, Verein Deutscher Ingenieure), and the publication codes (Pressekodex).

In addition, there is a technical design blog on "Codes-Designer Ethics" [19]. Many institutions and organizations now have codes of ethics. A code of ethics is not what ethic is, but what ethic code can be. This shows how important the impact of the ethical codes is in a society. A general feature of these codes is that they are common values accepted by individuals in that area [17].

Another term that needs to be dealt with in terms of ethics and codes is the concept of freedom. The acceptance of ethical rules by individuals is an indication of their freedom to choose. However, "Individuals who accept the codes of ethics with 'free will' shall also restrict their freedom by their own will" [17]. Because humans live in society and not alone, however, some generally accepted rules of ethics (ethical codes) will exist. People have some restrictions in society; for example, a person cannot kill someone, etc.

An approach to ethical principles and codes is within the scope of normative ethics. Normative ethics is a code of ethics that is based on a number of codes and accepts the common principles and norms accepted by societies and can be called rational ethics. Individuals and institutions or states that accept these principles and norms by agreement are deemed to have ethical responsibilities. Responsible persons, institutions, and states are audited by national or international ethics commissions and boards. National or 
international surveys and ratings are then published [20].

Design can be defined in the broadest sense as practical ideas for the solution of an existing problem. The definition of design, as per Turkey's Decree No. 554 of the Law Relating to the Protection of Industrial Designs, is:

Design refers to the whole or part of a product or the ornament on it, which is defined by the human senses, such as line, shape, shape, color, texture, material or flexibility, and the various elements or features perceived by it.

Another definition is: "Design is the appearance of various elements or features that can be perceived by human senses such as line, shape, color, shape, texture, material flexibility or embellishment of the whole or part of a product." [21].

Design is the process from idea to product. Essentially, an idea becomes a product through the following processes: problem definition (idea), research, inventing, finding solutions, selecting a solution, conceptual then detailed designs, manufacturing, and end product. The plan for the solution of a design problem is the "idea;" that is, the way in which the mind is portrayed. Each design has a mental representation (idea) and a corresponding object (product) [22].

Ideas first require imagination, then design, and ultimately productivity. Philosophy and imagination are the basis of the ethics of design. Imagination is one of the basic steps of thought. It is a set of reflections on a concept, entity, or idea in the human mind. It is not necessary for the objects/concepts that are first imagined to materialize but, as imagination can be considered valuable in the engineering field, it must adhere to certain scientific principles. This is where the ethical difference between the designer and philosopher begins. Design continues the process of shaping imagined objects into form (physical geometry), being innovative and ensuring compatibility with existing constraints, safety (risk analysis), and ethics. In general, design goes through the following stages: identifying the problem, obtaining the necessary information, conducting research for creative solutions, creating a model for the ideal solution (analytical solution), evaluating the preferred solution, and preparing the reports and plans. Design, drawing, process, and schema are required for constructing an object or system in the process of creating plans. The next step after the design is the implementation of the design (prototype product).

Industrial product design can develop solutions for consumer needs and problems for inventors, aesthetics, functionality, technical issues, ergonomics, material selection, salability, ethics, etc., and is a branch of science where comprehensive design requirements are to be taught and applied.

For centuries, people have pursued both aesthetics and best product designs to meet their needs and solve their problems. In a global competitive environment, where national boundaries are removed, it has become possible to stand out in competition with other firms by making good designs and satisfying their customers at a high level. However, although the design requirement is important, it is now known that using the design irresponsibly to harm human beings, the environment, or future generations can lead to irreparable damages [2].

For this reason, ethics and moral values that place a conscientious responsibility on the designer are already included in design requirements. Product design ethics should create the awareness that an industrial product should be ethically considered in the design stage, using the most important criteria, before it becomes harmful to the environment or humanity.

Designer ethics determines how designs should decide on their ethical principles (ethics + morals). The designer plans and determines all stages of a design. When viewed from this angle, if the designer is responsible for a product and the product's misuse is either certain or uncertain, he/she should have the authority to act ethically. The connection between the designer and the user is made with human-oriented design. The designer should be responsible for the availability of the designed product. Here, the designer has a connection with the product's ethical use. The designer should take the responsibility of using the design with the product's design features. The same applies to a systematic product with multiple parts, at all stages of development, because the final product creates a system of subassemblies and parts. This system is called a product tree, where each part and its subassemblies form an interconnected system, like a family tree. When performing risk analysis, each individual member of this family is subjected to a risk analysis. Ethically, each subsystem of the product should be analyzed ethically at all stages of development. Thus, it should be foreseeable whether each of its sub-products can be used elsewhere or is an unethical product. At this stage, the role and behavior of the system engineer are important for both the product and their ethical use of it.

In this age, science no longer confines itself to revealing only experimental facts, but also enters political and moral worldviews of society and further increases the authority of society. Scientism and technocracy, for example, explain all the problems of society according to technical knowledge, arguing that their solutions can only be derived through science and technique. The normative competence of science and technique is growing, thus increasingly moving away from the principle of the impartiality of science [6].

In addition, scientists and engineers have a role in society. With these roles, from an ethical point of view, it is expected that they have responsibilities different from those of other people. It is like a parent being responsible for a child up to a certain age. This is known as "preventive responsibility" [6].

Erdoğan Atakar stated, in 1997:

I thought about judging others, but I never thought of myself. According to me; ethic is a reflex. A reflex is 
from our genes, our family environment and our first years of education. In the following years, especially as your culture increases, your consciousness of citizenship, occupation, etc. is strengthened. Under the umbrella of the new concepts you will receive protection under the agenda. But your approach is always expanding by focusing on that first starting point.

These are the psychological and sociological dimensions of ethics, albeit from a biological perspective:

The design is the creative action followed to promote a product or service that considers a specific purpose based on planning. The design process involves the entire period from the idea stage to the application phase of a work. In order to be able to complete the design process, it is necessary to transform the thought created in the mind into an action and then into a form [23].

However, Kipöz and Atalay (2015) briefly explained the relationship between ethics and design [24]:

The concept of ethical design is concerned with the question of the conditions under which the design was created, produced, and consumed. Whether a design is ethical or not is a judiciary that is judged by an institutionalized design system and industry. Considering the main actors in this structure as designers, producers, and consumers, we can observe that the relationship between the actors is linear and hierarchical and that the designer and the producer play a manipulative role on the consumer.

Design and ethics should be considered as an integral whole. All stages and stakeholders of a designed product must respect the code of ethics and fulfill their responsibilities.

A product designed, in disregard of ethical requirements, can be harmful to itself, its environment, society, and people. Normally, the engineer, designer, and industrial product designer are in the design phase from the start. In other words, they have made important contributions since the product's formation. If these people make their designs responsive to the environment, and respectful to society and human values, their designs will be ethical; they will be more respected in society and more confident in their universal responsibility.

In terms of responsibility and ethics, the responsibility of the engineer is based on the individuals and institutions that they are responsible for [24]:

1. Responsibility toward society;

2. Responsibility to the profession;

3. Responsibility to the employer and client;

4. Responsibility for colleagues and subordinates;

5. Liability to oneself.

Science and technique are no longer ethically neutral, but bear some social responsibility. For this purpose, some firms address the society through slogans such as green architecture and ethical technique (United Nations
International Code of Conduct for Public Officials 1996).

In a globally competitive environment, it may not be enough to expect that everything can be designed ethically by simply putting responsibilities on the designer with a set of principles and codes. In addition, those who take and give responsibility cannot only be supported by ethical rules, but also by moral values based on social values.

\section{Ethics Committee and Commission}

Considering the case of Turkey, public institutions and personnel-related laws concerning ethical guidelines came into force in 2004 and 2005, when it was decided to establish an ethics committee and commissions related to the public [12].

The ethics committee of public officials has been established within the Prime Ministry, with 11 members. The Council of Ministers elects and appoints these members [16].

Laws and guidelines determine the authorities and responsibilities of the ethics committees and commissions. Individuals working in these committees also take responsibility for their duties and authority, as well as for supervision and reporting. An ethics committee can be composed of at least three people, and in association with the laws or guidelines.

Many institutions and organizations have ethics committees, such as for human rights and research, environmental issues, academics, students, universities, and scientific research [9].

\section{Rules of Design Ethics Including Engineering Ethics}

The Code of Ethics of Engineers should also apply to product designers. In a meeting of the World Engineers Association on October 5, 1977, the Fundamental Principles of Engineering Ethics were determined. These rules for engineers were written 50 years ago. However, these rules should be modified to apply to engineers and designers, and should be adapted to present-day ethical problems.

\section{Engineers:}

1. They shall prioritize the safety, health, and wellbeing of society while carrying out their professional duties.

2. They should only provide services in their area of expertise. (However, if an engineer is a specialist in many different areas, she/he can also serve in those areas. She/he should not serve with incomplete knowledge in an unfamiliar area.)

3. They shall publish only objective and actual official reports.

4. In professional matters, they shall act as trustworthy deputies for every employer or client and avoid conflicts of interest. 
5. They shall establish professional reputation for the validity of their services and not enter into unfair competition with others.

6. They shall work to uphold and improve the righteousness, dignity, and value of the profession.

7. They shall continue their professional development with their careers and provide opportunities for the professional development of engineers under their control [25].

In particular, product designers must comply with the following basic principles in order to preserve and improve the ethical standards, professional dignity, and dignity of their profession [7]:

1. Use knowledge and skills for the benefit of humanity.

2. Serve the society, employer, and customer in honesty and impartially, in loyalty.

3. Strive to increase the competence and reputation of the profession.

4. Support the professional and technical associations of their disciplines.

5. Reject bribery in any way.

6. Act fairly to all, regardless of factors such as race, religion, sex, age, origin, or physical disability.

\section{Ethical Strength of the Designer and Suggestions}

Is it ethical or not to design a product in areas with a lack of clarity about ethics? This may be in areas where the designer may have difficulty in making decisions. For example, one of the questions raised in the Introduction is whether war tools should be designed. Güneş S (2009) argued that the problem cannot be limited to only the designer, and that the use of weapons could be prevented or at least reduced by a balance between parties. It may be easier to set ethical principles for a child toy designer to choose non-poisonous materials or avoid sharp edges to prevent any damage to the child, which are probably in line with the vision of the company who hires the designer. However, it becomes more complicated when designing a plane, mobile phone, or autonomous car, which combines the expertise of several people. How would one program an autonomous car if one knows that there is a probability of crashing into a person crossing the street or crashing into a tree on the pavement or harming the person in the car? Or being a structural designer, can one control a civil aircraft designed to be equipped with military aids and electronic devices? Most of engineering and science history is full of examples of inventions that are used beyond the field for which they were developed, such as rockets, dynamite, TNT, or even LSD. Are designers preemptive enough to set every possible misuse of the product they design? At least, they have the responsibility to attempt to do so. They should take into account every aspect of the product they develop, including the ethical aspects, as a common practice in terms of calculating cost or risk issues, etc.

A product's design should solve a problem. The solution to the problem should answer the question of whether it is ethical or not, and should inform the stakeholders about the ethical problem. This product, albeit alone, is a part of a reprocessing product, but should behave like one product. However, a designer may not be able to make a decision about the ethics (because her/his hierarchical and functional range is too low). This situation would be too difficult to solve. In this situation, it is unfortunate that the designer lacks ethical strength, because the designer does not have the authority to violate the hierarchical order, and he/she cannot decide on the future ethical use of the final product or design solution.

There are also areas where it is unclear whether they are generally ethical or not. Producing atomic energy, obtaining thermal energy by fossil sources (causing air pollution), using natural resources unequally worldwide, cutting down forests, chemical drugs, etc. are fields in which the designer's ethical responsibility is requested in order to make ethical designs. Is it possible for an ethical designer to design products such as tools and machines for such fields? The state of the world cannot seem to find sufficiently understandable answers to this and similar universal questions.

Products designed in good faith, unfortunately, become bad due to bad usage. Can the possible misuse of designs be predicted? The question that arises is whether the designer could have added designs that prevented misuse. The risks that these products contain are analyzed when developing the products; possible risks are determined in advance and suggestions are made on what countermeasures should be taken. Uzun and Sağlam (2005) scientifically examined and proved that science and technology (and therefore, scientists and engineers) have responsibilities toward society. The sociological-political authority of science and technology has also increased. A parent is held responsible by the community for their child. Similarly, scientists and engineers have both moral and ethical responsibilities toward society. The fact that scientists and engineers can act according to its authority in decision mechanisms reveals another problem. The degree of responsibility by society that may arise in the future may be too large to measure, as in the case of "atomic bomb". How much can a scientist, engineer, or designer be responsible for ethical design? This issue will be discussed in more detail in the following sections.

In addition to the complexity of the system being designed, there is a multitude of stakeholders, including several designers, scientists, managers, and so on. A single stakeholder's unethical behavior can negatively affect ethical behavior overall and result in unethical consequences. However, if the designer thinks, at the beginning of designing a product, at the idea stage, whether the product may lead to unethical behaviors, then at least from the outset, all stakeholders can be warned to act informed, responsibly, and ethically. Thus, the designer's 
responsibility for providing information will be fulfilled.

Andreas Spahn (2011)'s concept of "persuasive technique" defines rational ethics, provides informative and persuasive techniques in many areas of technique, and makes a number of decisions that affect safety. When driving a car, for example, the speed, motor temperature, engine oil reduction, etc. can be used to warn the driver of possible risks. Andreas Spahn states that persuasive technique can be used effectively for stimulating persuasive technical ethics and suggests the following three principles [16]:

1. Ethical judgments should be based on rational principles, developed, supported, and used through rational evidence.

2. For an action to be moral, the action's motivation must also consider the role of the moral content of the rational insight.

3. The social realization and promotion of moral goals is best achieved by proposing, supporting, rationally measuring, and using effective decision methods, in both general and social decision mechanisms.

As can be seen, in some areas, the designer cannot carry the responsibility, but this does not change the reality of the work. In terms of usage, the design is either ethical or not. In other words, the designer should consider the possibility of unethical use in the design phase and show the authority and will to refuse to make the design. Paying attention to the following steps in an ethical decision-making challenge may be another guidance:

1. Define the problem to be decided.

2. Define stakeholders.

3. Define relevant basic ethical principles, laws, regulations, etc.

4. Define and evaluate alternative decisions and methods.

5. Search for a different opinion.

6. Decide on ethics and take action.

In case of a completed work or incorrect practice, if society knows that it may suffer obvious loss, action can be taken based on the designer's code of ethics, below:

1. Deliver the problem to the knowledge of those who are in a decision-making position and express your concern.

2. Try all ways to immediately make the necessary changes or interventions within the workplace to eliminate the harm.

3. Collect and inform the other observer of any objection that the work or practice is wrong and that the community will be harmed.

4. Produce evidence to the competent authorities.

\section{Vision of Ethical Design}

The challenge of ethical decisions and design constraints in design compels designers to comply with ethical committees or commissions. Perhaps the necessity of ethical design can open a new vision and work space for the designer. The BBC program, Ethical design period in the city, states the following:

"With the impact of natural disasters such as droughts and floods, fashion designers are now looking for more environmentally sensitive designs. In addition, some of the rich chain of stores is being criticized with increasingly severe arguments about their workmanship practices. Designers say that elegance and environmental sensitivity can being or exist together" [26].

"Everyone needs to become specialized in their field. But when a human is copying a design, he must know that hundreds of people are entitled (Saying: Justice is the foundation of property!)" [27].

In 2011, the German Industrial Designer Association (VDID) adopted and published "The ethics for designers" codex in the general assembly [18]. The codex is intended to guide business behavior and daily work responsibilities. The most remarkable sentence of the codex is as follows: "Industrial designers always take people into consideration. Similarly, in other requirements, good design always meets people's functional, psychological, and social-cultural design needs" [28]. A good design must be also effective in terms of energy, complexity, usefulness, etc.

For a livable world in which humans can fulfill their conscientious responsibility toward future generations, designs should be created taking ethical rules into account.

\section{Conclusions}

This paper described the designer's responsibility to society and future humanity. It defined and drew an abstract framework for design ethics, then described common concepts for it and how design and ethics are interconnected. The starting points of both design and ethics are ideas and thoughts. Design is the geometry of the shape - the shaping and drawing of thought. The geometric form is now able to be questioned. The figure is either ethical or unethical, while, in the idea stage, it was not. It is important to consider ethics in all the ongoing stages of design and the life cycle of the subsequent product. This paper attempted to reveal the ethical principles and codes in terms of the designer's ethical responsibilities.

It emphasized that good designs are also ethical designs, and that the designer has a responsibility to take ethical requirements into account. Conducting risk analyses and countermeasures of the designed products before use have been proposed, and ethical analyses should be performed in a similar way.

This paper identified that designers face difficult decision-making challenges when designing in some industries, such as the defense industry or other sectors; in 
such cases, they have ethical responsibilities such as informing their supervisor. It described measures to enhance the ethical strength of the designer and offered some effective suggestions to solve the related issues. The designer's minimum responsibility is to inform parties about all stages of the product life cycle. All the stages and stakeholders of a designed product must respect the code of ethics and fulfill their responsibilities. Thus, the responsibility for information will be fulfilled.

As a result, excellent designs would be those where the designer takes social responsibility and the ethical measures of a designed product into account. If we want to entrust a livable world for our children in the future, then the ethical design criterion should be adapted and implemented as one of the basic principles of design requirements.

\section{REFERENCES}

[1] Erdoğan, N., Tekin, Ş., Cultural Faith Park Project-Mor Yakup Church Excavation (Kültür İnanç Park1 Projesi-Mor Yakup Kilisesi Kazıs1) 22. Museum Studies and Recovery Excavations Symposium 14-17 Nov. 2013, Adana-Turkey, Principal Publication No: 341, General Directorate of Cultural Heritage and Museums, Publication No: 166, 2013

[2] Torunoğlu, E., Environmental ethics and environmental engineering lecture notes. Anadolu University, Turkey. Online resource. https://studylibtr.com/doc/1112250/slayt1---anadolu-üniversitesi, acc. 01.04.2019, 2014.

[3] Metzler, J. B., Manual technology ethics (Handbuch technikethik). Publisher: Metzler Verlag, J.B., Stuttgart-Germany, 2013.

[4] TESKON (1997). National Installation Engineering Congress and Exhibition, 20-23 November 1997, Proceedings book of MMO Chamber of Mechanical Engineers Release number: 203/2, İzmir, Turkey.

[5] Norwich University Online, Who Were the Manhattan Project Scientists? Webpage. https://online.norwich.edu/ac ademic-programs/resources/who-were-the-manhattan-proje ct-scientists, acc. 01.04.2019, 2017.

[6] Uzun, N., \& Sağlam, N., The effect of socio-economic situation on environmental awareness and environmental academic success, Hacettepe University Journal of Education 29, 194-202, 2005.

[7] Demirkol, M., Lecture Manuscript: İML 111 Introduction to manufacturing engineering - science and engineering ethics. Internet. https://slideplayer.biz.tr/slide/12074726/, acc. 01.04.2019, 2011.

[8] Güneş, S., Weapons, design and Kalashnikov AK-47. Journal of Art and Design, 1(4), 35-52. Online resource. http://dergipark.gov.tr/sanatvetasarim/issue/20663/220430, acc. 01.04.2019, 2009 .

[9] Kaylan A.R., Engineering ethics, national prestige and competitiveness. First National Engineering Congress and 8th Meeting of Council of Engineering Deans, 20-22 May
2004, İzmir, Turkey. Online resource.http://web.deu.edu.tr /umk/sunum/s5.pdf, acc. 01.04.2019, 2004.

[10] Bogner Ethics Guide. Online resource. https://webdosya.cs b.gov.tr/db/destek/editordosya/Bakanlik_Etik_Rehberi.pdf, acc. 01.04.2019.

[11] TMMOB (2003). Principles of Professional Behavior, 2003 Congress Decisions, Turkish Union of Chambers of Architects and Architects. Homepage.https://www.tmmob. org.tr/en/node/9793, acc. 01.04.2019.

[12] Law no. 5176 (2004). On the establishment of an ethics committee and amendments to some laws. Accepted on 25 May 2004, Turkey. Online resource. http://etik.gov.tr/wp-c ontent/uploads/2019/02/5176sayilikanun.pdf, acc. 01.04.20 19.

[13] Regulation (2005). Principles of ethical conduct of public servants and the principles and procedures of application. Regulation, 13/04/2005, Turkey.

[14] Turkish Government Ethics Committee (2012). Ethics guide, public officials. Ankara, Turkey. Online resource. https://studylibtr.com/doc/1712946/kamu-g\%C3\%B6revlil eri-etik-rehberi, acc. 01.04.2019.

[15] Avrupa Patent (2019). Avrupa Patent website. Webpage. http://www.avrupapatent.com.tr/en/, acc. 01.04.2019.

[16] Turkish Government Ministry of Environment and Urbanization 2014.

[17] Spahn, A., Moral machines? Persuasive technology as a challenge for rationalist ethics (Moralische maschinen? Persuasive technik als herausforderung für rationalistische ethike). DGPhil-Kongress 2011. Sektion: Technikphilosop hie. Webpage.https://epub.ub.uni-muenchen.de/12596/1/A Spahn-Moralische_Maschinen-DGPhil_2011.pdf, acc. 01.04.2019, 2011.

[18] Fuchs, J., Personal responsibility and Christian morality, Georgetown University Press, Washington, D.C. 20057, ISBN 0-87840-405-8, 1983.

[19] Blog Technisches Design (2012). The codex - ethics for the designer (Der codex-Ethik für designer). Blog Post. http://technischesdesign.mw.tu-dresden.de/blog/der-codex$\% \mathrm{E} 2 \% 80 \% 93$-etKınıkhik-fur-designer/, acc. 01.04.2019.

[20] OECD (2000). Trust in government: Ethics measures in OECD countries. Organisation for Economic Co-operation and Development. Report. Online resource. http://www.oe cd.org/governance/ethics/48994450.pdf, acc. 01.04.2019.

[21] Togay, A. \& Biyıkçı, E., Design technology interaction, 2014-Fall semester graduate course. Gazi University, Ankara, Turkey. Online resource. https://docplayer.biz.tr/6 265283-Tasarim-teknoloji-etkilesimi-lisansustu-dersi-kavr amsal-temeller-togay-a-biyikci-e-1-giris.html, acc. 01.04.2 $019,2014$.

[22] Franz, J.H., Ethic codes and values (Ethikkodizes und werte), Berlin Technische Universität Berlin, 29. April 2013. Online resource. http://www.blue-engineering.org/i mages/0/0b/Franz_Ethikkodizes_und_Werte_-_Moral_pre digen ist leicht $\% \overline{2} \mathrm{C}$ Moral begründen schwer. pdf, acc. 01.04.2019, 2013.

[23] Kınık, M., Plagiarism and ethics in graphic design (Grafik tasarımda intihal ve etik), International Journal of 
Humanities and Education, 1:2, 304-322, http://www.ijhe. org/Published/201510_002_1_008.pdf, acc. 01.04.2019, 2015.

[24] Kipöz, Ş., \& Atalay, D., Promises and conflicts of ethical fashion within the context of its representation: how ethically is "ethical fashion" presented? Art, Design and Science Journal, 2015, 14, 101-115. http://dergipark.gov.tr /download/article-file/203779, acc. 01.04.2019, 2015.

[25] Gençoğlu, M.T., Ethics in engineering. EMO Chamber of Electrical Engineers, Ankara news bulletin number: 2008.5, Ankara, Turkey. Webpage.: http://www.emo.org.tr/ekler/2 c6dec66eada084_ek.pdf?dergi=527, acc. 01.04.2019, 2008.

[26] BBC News (2010). In Mode: Ethical design period. Webpage. http://www.bbc.co.uk/turkce/multimedya/2010/09/100824 vid_ethical fashion.shtml, acc. Sept. 2010.

[27] Atakar, E., Ethical problems of design engineer, MMO Union of Mechanical Engineers, III. National Installation Engineering Congress and Exhibition, MMO publication no: 203/3, November 1997, İzmir, Turkey, 89-92, 1997.

[28] ABET (1977), Code of Ethics of Engineers-The Fundamental Principles, Approved by the Board of Directors, October 5, 1977, Accreditation Board for Engineering and Technology (ABET) 415 North Charles Street Baltimore, MD 21201, Online resource.https://engin eering.purdue.edu/MSE/academics/undergraduate/ethics.p df, acc. 07.04.2019. 